Ethos (Jurnal Penelitian dan Pengabdian Masyarakat): 304-312

\title{
Sistem Pendukung Keputusan Pemilihan Perusahaan Pengangkutan Barang Menggunakan Metode SaW di PT. Indah Kiat Pulp and Paper Tbk. SERANG MiLL
}

\author{
THE DECISION SUPPORT SYSTEM FOR THE SELECTION OF GOODS TRANSPORTATION COMPANY \\ Using SAW METHOd IN PT. INDAH KiAT PULP \& PAPER TBK. SERANG MILL \\ ${ }^{1}$ Saefudin, ${ }^{2}$ Eka Hendriana \\ ${ }^{1,2}$ Teknik Informatika, Fakultas Teknologi Informasi, Universitas Serang Raya \\ Jl. Raya Serang - Cilegon Km. 05 (Taman Drangong), Serang, Banten \\ E-mail : 'dinsaefudin@yahoo.co.id, ${ }^{2}$ ekahendriana08@gmail.com
}

\begin{abstract}
The purpose of this study is to create the decision support applications for election of goods transportation company using SAW method. This method can determine the weight score for each attributes that selects the best alternative from a number of other alternatives, in this case the alternative in this question is it is suitable for being associate with the goods transportation company based on predetermined criteria. The results of the calculation of SAW method is in the form of ranking where the greatest score will be accepted as a reference for company partners. With this method, it is expected to obtain an accurate assessment, because that based on the score of the predetermined criteria which will get the results as objective as possible and to facilitate the selection process effectively.

Keywords: Decision Support Systems, Simple Additive weighting method, goods transporting
\end{abstract}

\begin{abstract}
Abstrak. Tujuan penelitian ini adalah untuk membangun aplikasi pendukung keputusan pemilihan perusahaan pengangkutan barang dengan menggunakan metode SAW. Metode ini dapat menentukan nilai bobot untuk setiap atribut yang akan menyeleksi alternatif terbaik dari jumlah alternatif lainnya, dalam hal ini alternatif yang dimaksud adalah yang berhak diterima menjadi rekanan perusahaan pengangkutan barang berdasarkan kriteria yang telah ditentukan. Hasil yang diperoleh dari perhitungan metode SAW berupa perankingan dimana nilai terbesar merupakan nilai yang akan menjadi referensi perusahaan diterima menjadi rekanan. Dengan metode tersebut diharapkan penilaian akan lebih akurat, karena didasarkan pada nilai kriteria yang sudah ditentukan sehingga akan mendapatkan hasil seobjektif mungkin dan dapat memudahkan dalam proses pemilihannya secara efektif.

Kata kunci : Sistem Pendukung Keputusan, Metode Simple Additive Weighting, pengangkutan Barang
\end{abstract}




\section{Pendahuluan}

\section{Latar Belakang}

PT. Indah Kiat Pulp and Paper Serang Mill bertindak sebagai supplyer packaging product terbesar. Data terakhir Customer Produk Packaging mencapai 200 perusahaan (Sumber : Realisasi delivery report, 25 Oktober 2015). Customer tersebar dibeberapa wilayah di indonesia mulai dari area Jabodetabek, Jawa Barat, Jawa Tengah, Jawa Timur, dan Sumatera dengan Jumlah barang yang dipesan dan dikirim ke Customer tidak sedikit. Permintaan pengiriman ke Customer setiap bulannya rat-rata untuk area Jabodetabek 8000 Ton, Jawa barat 4000 Ton, Jawa tengah 555 Ton, Jawa Timur 230 Ton, Lampung 100 Ton, Riau 800 Ton, Pekan Baru 180 ton, Medan 130 Ton dan Manado 80 Ton (Sumber : Realisasi delivery report January-October 2015, 25 Oktober 2015). Berdasarkan data tersebut, untuk dapat memenuhi permintaan pengiriman tentu harus di dukung oleh armada kendaraan yang mencukupi untuk pengiriman barang.

Proses melakukan kerja sama dengan perusahaan luar dengan cara lelang/tender baik yang dilakukan secara konvensional membutuhkan suatu pendukung keputusan dalam pemilihan pemenangnya. Sistem yang berjalan selama ini sebatas mencatat peserta lelang dan berkas-berkas yang di persyaratkan, sehingga pengambil keputusan masih harus bekerja dalam memilih dan menentukan pemenang.

Cara tersebut masih sering menimbulkan permasalahan seperti munculnya sanggahan dari peserta lelang/tender yang tidak puas dengan hasil keputusan pemenang lelang/tender. Banyaknya peserta yang mengikuti sehingga dibutuhkan waktu yang lama untuk mengevaluasi seluruh dokumen penawarannya. Proses evaluasi kualifikasi dilakukan dengan meminta memeriksa semua dokumen penawaran.

ini masih menggunakan cara manual yaitu dengan tenaga manusia yang membuat kinerja nelayan menjadi tidak optimal dan terbilang lambat.

\section{Identifikasi Masalah}

Identifikasi masalah yang didapat berdasarkan latar belakang diatas adalah sebagai berikut :

1. Belum ada suatu sistem pendukung keputusan yang terkomputerisasi dengan baik dalam bentuk aplikasi

2. Proses pemilihan perusahaan pengangkutan barang masih dilakukan secara manual sehingga proses pemilihannya kurang efisien

\section{Rumusan Masalah}

Pada penelitian ini memiliki permasalahan yang harus ditelaah, antara lain :

1. Bagaimana membangun aplikasi SPK dalam proses pemilihan perusahaan pengangkutan barang dengan menggunakan metode SAW?

2. Bagaimana menerapkan sebuah aplikasi pendukung keputusan agar proses pemilihan berjalan lebih efisien? 


\section{Batasan Masalah}

Batasan masalah pada penelitian ini adalah sebagai berikut :

1. Penelitian ini membahas pemilihan perusahaan pengangkutan barang untuk support delivery packaging product ke Customer

2. Pada penelitian ini menggunakan metode Simple Additive Weighting (SAW)

3. Peserta dalam penelitian ini adalah perusahaan yang sebelumnya tidak pernah melakukan kerja sama dengan perusahaan.

\section{Tujuan Penelitian}

Tujuan pada penelitian ini adalah sebagai berikut :

1. Membangun aplikasi SPK dalam proses pemilihan perusahaan pengangkutan barang untuk utuk dijadikan rekanan.

2. Menerapkan sistem dalam penentuan pemilihan perusahaan pengangkutan barang.

\section{Metodologi Penelitian}

Penelitian dilakukan dengan beberapa tahapan guna mendapatkan data dan informasi yang akurat, meliputi:pengumpulan data, analisis, perancangan sistem, pembuatan aplikasi, uji coba dan implementasi.

\section{Dasar Teori}

\section{Sistem Pendukung Keputusan (SPK)}

Konsep Sistem Pendukung Keputusan (SPK) /Decision Support Sistem (DSS)pertama kali diungkapkan pada awal tahun 1970-an oleh Michael S. Scott Morton dengan istilah Management Decision Sistem yaitu suatu sistem yang berbasis komputer yang ditunjukan untuk membantu pengambilan keputusan dengan memanfaatkan data dan model tertentu untuk memecahkan berbagai persoalan yang tidak terstruktur.Istilah SPK mengacu pada suatu sistem yang memanfaatkan dukungan komputer dalam proses pengambilan keputusan.

\section{Perusahaan Pengangkutan Barang}

Pengertian dari Jasa Pengurusan Transportasi (freight forwarding) atau perusahaan pengangkutan barang adalah usaha yang ditujukan untuk mewakili kepentingan pemilik barang untuk mengurus semua kegiatan yang diperlukan bagi terlaksananya pengiriman dan penerimaan barang baik melalui transportasi darat, transportasi laut atau transportasi udara

\section{MetodeSimple AdditiveWeighting(SAW)}

Metode Simple Additive Weighting (SAW) adalah Metode penjumlahan terbobot. Konsep dasar Metode SAW adalah mencari penjumlahan terbobot dari rating kinerja pada setiap alternatif pada semua kriteria. Metode SAW membutuhkan proses 
normalisasi matriks keputusan (X) kesuatu skala yang dapat dibandingkan dengan semua rating alternatif yang ada. Metode SAW mengenal 2 (dua) atribut yaitu kriteria keuntungan (benefit) dan kriteria biaya (cost). Perbedaan mendasar dari kedua kriteria ini adalah dalam pemilihan kriteria ketika mengambil keputusan.

\section{Unified Modelling Language (UML)}

UML adalah bahasa spesifikasi standar untuk mendokumentasikan, menspesifikasikan dan membangun sistem perangkat lunak. Dengan menggunakan UML kita dapat membuat model untuk semua jenis aplikasi perangkat lunak, dimana aplikasi tersebut dapat berjalan pada perangkat keras, sistem operasi dan jaringan apapun, serta ditulis dalam bahasa pemrograman apapun. UML menyediakan jenis-jenis diagram untuk memodelkan pemrograman berorientasi objek atau Object Oriented Programing (OOP). Dimana terdapat beberapa diagram untuk menunjukan simbol elemen model yang disusun untuk mengilustrasikan bagian atau aspek tertentu dari sebuah sistem.

\section{Analisa dan Perancangan Sistem}

\section{Analisis Sistem Yang Sedang Berjalan}

Analisis sistem merupakan gambaran tentang sistem yang saat ini sedang berjalan di PT. Indah Kiat Pulp and Paper Tbk. Serang Mill pada bagian Delivery Packaging Product. Dimana sistem yang selama ini berjalan yaitu pihak perusahaan jasa pengangkutan barang memberikan penawaran-penawaran kepada pihak bagian Delivery di PT. Indah Kiat Pulp and Paper Tbk. baik itu penawaran harga per-satu ritnya atau jenis kendaraan yang disediakan oleh pihak perusahaan jasa pengangkutan barang tersebut. Berikut ini prosedur pengangkutan barang antara lain :

1. Bagian Delivery menghitung kebutuhan kendaraan berdasarkan baseline data dan target

2. Bagian Delivery mengundang perusahaan pengangkutan barang

3. Perusahaan pengangkutan barang mengajukan penawaran

4. Melakukan proses analisa pada aplikasi SPK pengangkutan barang

5. Hasil analisa dibahas bersama dengan unsur pimpinan terkait

6. Bagian Delivery menyerahkan Form Vendor sebagai tanda bukti perusahaan pengankutan barang diterima menjadi rekanan.

\section{Analisis Perhitungan Metode Simple Additive Weighting (SAW)}

Berikut langkah-langkah perhitungan untuk mencari nilai akhir

1. Menentukan alternatif dan kriteria :

$\mathrm{A}_{1}=$ PT. Daya Eka Samudera

A2 $=$ CV. Jasatama Mandiri

A3 = CV. Angkutan Terang Mandiri

A4= PT. Gunung Sakti Makmur 
A5= PT. Djasa Sumatera

Kriteria yang digunakan adalah sebagai berikut :

$\mathrm{C} 1$ = Evaluasi Administrasi

$\mathrm{C} 2=$ Evaluasi teknis

C3 = Evaluasi Harga

2. Memberikan nilai rating kecocokan setiap alternatif pada setiap kriteria, ditunjukan pada tabel berikut ini

Tabel 3.1 Nilai Rating Kecocokan

\begin{tabular}{|c|l|c|}
\hline No & \multicolumn{1}{|c|}{ Kriteria } & Nilai \\
\hline 1 & $\begin{array}{l}\text { Evaluasi } \\
\text { Administrasi }\end{array}$ & $0,1,2$ \\
\hline 2 & Evaluasi Teknis & $0,1,2$ \\
\hline 3 & Evaluasi Harga & Penawaran/HPS \\
\hline
\end{tabular}

Berdasarkan hasil wawancara dan observasi bersama unsur pimpinan dibagian Delivery dan pembimbing lapangan didapat nilai harga dan penawaran sebagai berikut :

Tabel 3.8 Nilai Kriteria Harga

\begin{tabular}{|c|l|c|c|c|}
\hline No & Alternatif & HPS & Penawaran & $\mathrm{C}_{3}$ \\
\hline 1 & A1 & $17,363,000$ & $17,450,000$ & 1.0050 \\
\hline 2 & A2 & $17,363,000$ & $17,300,000$ & 0.9954 \\
\hline 3 & A3 & $17,363,000$ & $17,380,000$ & 1.0010 \\
\hline 4 & A4 & $17,363,000$ & $17,400,000$ & 1.0021 \\
\hline 5 & A5 & $17,363,000$ & $17,420,000$ & 1.0033 \\
\hline
\end{tabular}

Menentukan bobot preferensi atau tingkat kepentingan (W) setiap kriteria, nilai bobot preferensi untuk setiap kriteria adalah sebagai berikut :

$\mathrm{W}=[3,3.4]$

Membuat matrik keputusan yang dibentuk dari tabel rating kecocokan dari setiap alternative pada setiap kriteria

$$
\mathrm{x}=\left[\begin{array}{lll}
2 & 2 & 1.0050 \\
2 & 2 & 0.9964 \\
2 & 1 & 1.0010 \\
1 & 2 & 1.0021 \\
2 & 2 & 1.0033
\end{array}\right]
$$

Melakukan proes normalisasi matrik keputusan dengan cara menghitung nilai rating kinera ternormalisasi $\left(\mathrm{r}_{\mathrm{ij}}\right)$ berdasarkan persamaan yang disesuaikan dengan jenis kriteria. Untuk kriteria evaluasi administrasi dan evaluasi teknis menggunakan kriteria keuntungan (benefit) sedangkan untuk kriteria harga menggunakan kriteria biaya (cost). $\mathrm{r}_{11}$

$$
\begin{aligned}
& \mathrm{r}_{11}=\frac{2}{\operatorname{Max}_{i}(22212)}=\frac{2}{2}=1.0000 \\
& \mathrm{r}_{12}=\frac{2}{\operatorname{Max}_{i}(22122)}=\frac{2}{2}=1.0000 \\
& \mathrm{r}_{13}=\frac{\operatorname{Min}_{i}(1.00500 .99641 .00101 .00211 .0033)}{1.0050}=\frac{0.9964}{1.0050}=0.9914
\end{aligned}
$$




$$
\begin{aligned}
& \mathrm{r}_{21}=\frac{2}{\operatorname{Max}_{i}(22212)}=\frac{2}{2}=1.0000 \\
& \mathrm{r}_{22}=\frac{2}{\operatorname{Max}_{i}(22122)}=\frac{2}{2}=1.0000 \\
& \mathrm{r}_{23}=\frac{\operatorname{Min}_{i}(1.00500 .99641 .00101 .00211 .0033)}{0.9964}=\frac{0.9964}{0.9964}=1.000 \\
& \mathrm{r}_{31}=\frac{2}{\operatorname{Max}_{i}(22212)}=\frac{2}{2}=1.0000 \\
& \mathrm{r}_{32}=\frac{1}{\operatorname{Max}_{i}(22122)}=\frac{1}{2}=0.5000 \\
& \mathrm{r}_{33}=\frac{\operatorname{Min}_{i}(1.00500 .99641 .00101 .00211 .0033)}{1.0010}=\frac{0.9964}{1.0010}=0.9954 \\
& \mathrm{r}_{41}=\frac{1}{\operatorname{Max}_{i}(22212)}=\frac{1}{2}=0.5000 \\
& \mathrm{r}_{42}=\frac{2}{\operatorname{Max}_{i}(22122)}=\frac{2}{2}=1.0000 \\
& \mathrm{r}_{43}=\frac{\operatorname{Min}_{i}(1.00500 .99641 .00101 .00211 .0033)}{1.0021}=\frac{0.9964}{1.0021}=0.9943 \\
& \mathrm{r}_{51}=\frac{2}{\operatorname{Max}_{i}(22212)}=\frac{2}{2}=1.0000 \\
& \mathrm{r}_{52}=\frac{2}{\operatorname{Max}_{i}(22122)}=\frac{2}{2}=1.0000 \\
& \mathrm{r}_{53}=\frac{\operatorname{Min}_{i}(1.00500 .99641 .00101 .00211 .0033)}{1.0033}=\frac{0.9964}{1.0033}=0.9931
\end{aligned}
$$

Hasil dari nilai rating kinerja ternormalisasi akan membentuk matrik ternormalisasi sebagai berikut :

$$
\mathrm{R}=\left[\begin{array}{lll}
1.0000 & 1.0000 & 0.9914 \\
1.0000 & 1.0000 & 1.0000 \\
1.0000 & 0.5000 & 0.9954 \\
0.5000 & 1.0000 & 0.9943 \\
1.0000 & 1.0000 & 0.9931
\end{array}\right]
$$

Dari hasil normalisasi matrik diatas didapat nilai preferensi sebagai berikut :

$$
\begin{aligned}
\mathrm{V} 1 & =\{(1.0000)(3)+(1.0000)(3)+(0.9914)(4)\}=9,9656 \\
\mathrm{~V} 2 & =\{(1.0000)(3)+(1.0000)(3)+(1.0000)(4)\}=10,0000 \\
\mathrm{~V} 3=\{(1.0000)(3)+(0.5000)(3)+(0.9954)(4)\} & =8,4816 \\
\mathrm{~V} 4 & =\{(0.5000)(3)+(1.0000)(3)+(0.9943)(4)\}=8,4770 \\
\mathrm{~V} 5 & =\{(1.0000)(3)+(1.0000)(3)+(0.9931)(4)\}=9,9724
\end{aligned}
$$

Nilai terbesar adalah pada V2 sehingga alternative A2 adalah rekomendasi alternative yang terpilih sebagai alternatif terbaik (pemenang).

\section{Perancangan Sistem}

\subsubsection{Use Case Diagram}

Diagram Use Case adalah sebuah Use Case diagram untuk menjelaskan kebutuhan dari sisi pengguna (user). 


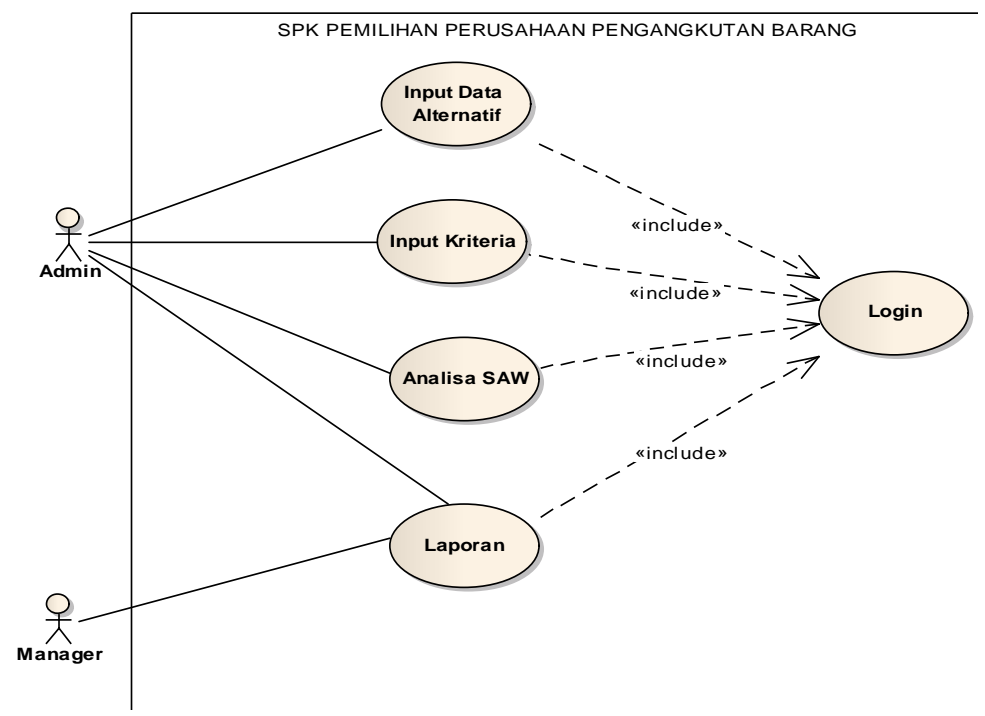

Gambar 3.2 Diagram Use Case

\subsubsection{Activity Diagram}

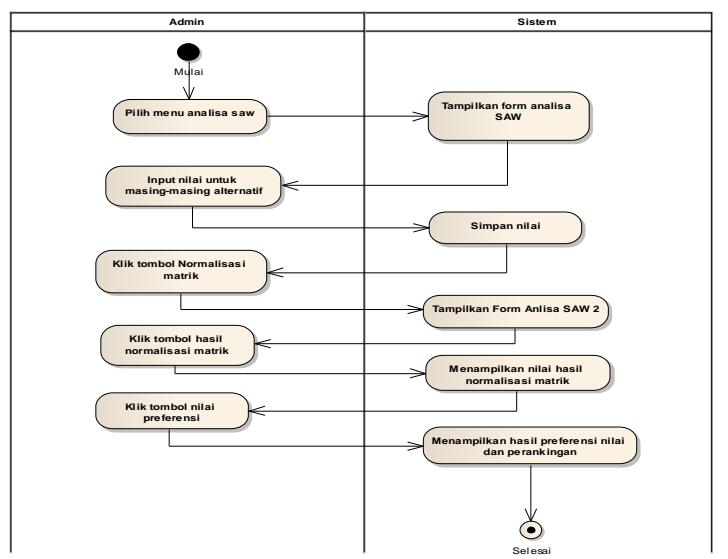

\section{Impelementasi}

\section{Halaman Menu Utama}

Halaman utama merupakan form yang berfungsi untuk mengakses halamanhalaman atau form yang terdapat dalam aplikasi. halaman ini akan tampil ketika admin telah berhasil login maka admin dapat mengakses halaman yang ada sesuai kebutuhan. 


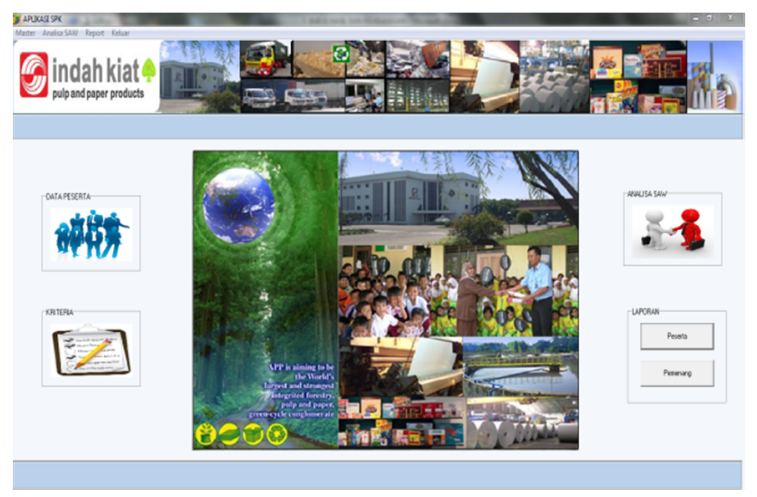

Gambar 4.1 Menu Utama

\section{Halaman Analsia SAW}

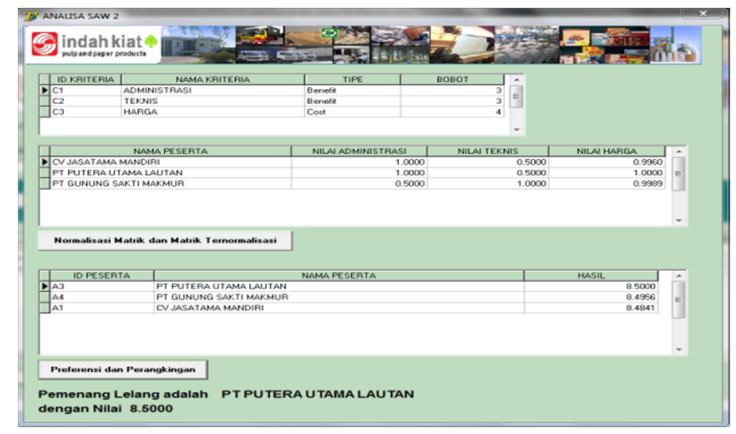

Gambar 4.2 Analisa SAW

\section{Kesimpulan dan Saran}

\section{Kesimpulan}

Setelah melakukan analisa, perancangan dan implementasi sistem yang dilanjutkan dengan pengujian sistem, maka dapat ditarik beberapa kesimpulan sebagai berikut :

1. Aplikasi sistem pendukung keputusan pemilihan perusahaan pengangkutan barang dibangun menggunakan Delphi 7.0 dan MySQL dan perancangan sistem menggunakan UML

2. Dalam memodelkan masalah pemilihan perusahaan pengangkutan barang kedalam metode Simple Additive Weighting adalah dengan menentukan kriteria dan nilai bobot kemudian dihitung dengan menggunakan metode SAW. Setelah dilakukan perhitungan berdasarkan metode SAW didapatkan hasil berupa perankingan dari nilai hasil test tertinggi Dari hasil test tertinggi inilah yang menjadi refernsi perusahaan pengangkutan yang akan diterima menjadi rekanan

\section{Saran}

Untuk menyempurnakan sistem yang dibuat, maka memeberikan saran-saran sebagai berikut : 


\section{2 | Saefudin, et al.}

1. Setelah sistem ini berjalan dan digunakan disarankan agar pihak pengguna melakukan pemeliharaan dan perawatan dengan baik agar sistem ini bisa tetap digunakan dan dapat dikembangkan menjadi lebih sempurna.

2. Seiring perkembangan teknologi informasi, maka akan lebih baik jika sistem yang ada sekarang kedepannya dikembangkan lagi dengan menggunakan teknologi jaringan sehingga dalam penggunaannya dapat dilakukan ditempat yang berbeda.

3. Untuk memperluas pembahasan dapat ditambahkan dengan kriteria lain.

\section{Daftar Pustaka}

Etika, Wahyu Perdani. (2014). Sistem Pendukung Keputusan Penerimaan Siswa Baru Dengan Metode Simple Additive Weighting (SAW). Edu Komputikal Journal. Vol. 1. No. (1)

Fajar Nugraha, Bayu Surarso, Beta Noranita. (2012). Sistem Pendukung Keputusan Evaluasi Pemilihan Aset dengan Metode Imple Additive Weighting, Jurnal Sistem Informasi Bisnis

Kusrini. (2007). Strategi Perancangan dan Pengelolaan Basis Data. Yogyakarta : Andi

Nugroho, B. (2004). Database Relational Dengan MySQL. Yogyakarta : Andi

Kusrini. (2007). Konsep dan Aplikasi Sistem Pendukung Keputusan. Yogyakarta : Andi

Rina, Hasanah. (2013). Sistem Pendukung Keputusan Untuk Menentukan Penerimaan Beasiswa Dengan Metode Simple Additive Weighting (SAW) (Studi Kasus Pada MTS Al-Maidah Kotasan). Pelita Informatika Budi Darma. Vol. 5. No. (3)

Peraturan Presiden RI No. 54 Tahun 2010, 2010. Pengadaan Barang atau Jasa.

Sri, Eriyait. (2011). Perancangan Sistem Pendukung Pengambilan Keputusan Untuk Penerimaan Beasiswa Dengan Metode SAW, Jurnal Teknologi Informasi Dinamik. Vol.16. No. (2). 171-176

Turban, E. (2015). Decision Support System and Intellegent System. Yogyakarta : Andi Offiset 